\title{
Dissimilaridade genética em variedades de Artemisia annua L. embasada em caracteres agronômicos, fisiológicos e fitoquímicos
}

\author{
BOLINA, C.O.'; MARCHESE, J.A. ${ }^{*}$; PALADINI, M.V.1; PINNOW, C.1; BENIN, G.1; SOUSA, I.M.O.2; FOGLIO, \\ M.A. ${ }^{2}$ \\ 'Laboratório de Bioquímica e Fisiologia Vegetal; Universidade Tecnológica Federal do Paraná, Campus Pato \\ Branco, Via do Conhecimento, Km 01, CEP 85503-390, Pato Branco-PR, Brasil *abramo@pq.cnpq.br \\ ${ }^{2}$ Centro Pluridisciplinar de Pesquisas Químicas, Biológicas e Agronômicas, Universidade Estadual de Campinas, \\ Caixa Postal 6171, 13081-970, Paulínia-SP, Brasil.
}

\begin{abstract}
RESUMO: O presente estudo objetivou estimar a variabilidade genética existente entre caracteres agronômicos, fisiológicos e fitoquímicos em variedades de $A$. annua. $O$ delineamento experimental foi inteiramente casualizado e os tratamentos foram as variedades Artemis,

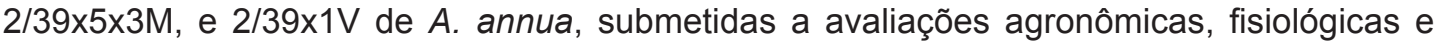
fitoquímicas. Para a realização das estimativas de distância genética foram geradas matrizes de dissimilaridade utilizando a distância Euclidiana e os métodos de agrupamento de Tocher e UPGMA. Além disso, avaliou-se a importância relativa dos caracteres para divergência genética pelo método de Singh. As análises foram realizadas pelo software Genes e os dendrogramas obtidos pelo NTSYS. A presença de variabilidade genética dentro das variedades permitiu a identificação de acessos dissimilares e com média elevada para as características estudadas. O número de ramificações, concentração intracelular de $\mathrm{CO}_{2}$ e o rendimento de óleo essencial foram os caracteres que mais contribuíram para a dissimilaridade genética de $A$. annua. Os acessos B24, C5 e C32 foram os mais promissores dentro das variedades e devem ser conservados para futuras hibridações, sendo que as hibridações mais promissoras na obtenção de populações segregantes desejadas são B24 x C5, B24 x C32 e C5 x C32.
\end{abstract}

Palavras-chave: Artemisinina, Óleo essencial, Variabilidade, Seleção de genitores.

ABSTRACT: Genetic dissimilarity in varieties of Artemisia annua L. based on agronomic, physiological and phytochemical characters. This study aimed to estimate the genetic variability among agronomic, physiological, and phytochemical characters in varieties of $A$. annua. The experimental design was completely randomized and the treatments were the varieties Artemis, $2 / 39 \times 5 \times 3 \mathrm{M}$ and $2 / 39 \times 1 \mathrm{~V}$ of $A$. annua, subject to agronomic, physiological and phytochemical evaluations. To estimate the genetic distances, dissimilarity matrices were generated using the Euclidean distance and the Tocher and UPGMA grouping methods. Moreover, we evaluated the relative importance of the characters for genetic divergence through the method of Singh. The analyses were performed in the Genes software and the dendrograms were obtained from the NTSYS program. The presence of genetic variability within the varieties allowed the identification of dissimilar accessions with high average for all traits. The number of branches, intracellular concentration of $\mathrm{CO} 2$ and oil yield were the traits that contributed most to the genetic dissimilarity of $A$. annua. The accessions B24, C5 and C32 were the most promising within the populations and must be conserved for future crossings, and the most promising crosses to obtain the desired segregant populations were B24 x C5, B24 x C32 and C5 x C32.

Keywords: Artemisinin, Essential oil, Variability, Selection of parents.

\section{INTRODUÇÃO}

Artemisia annua L. (Asteraceae) é uma espécie aromática anual, com hábito de crescimento determinado (Ferreira \& Janick, 1996) e altura variando de 2 a 3 metros (Brisibe et al., 2009). É uma planta de dias curtos obrigatória (Marchese et al., 2002), com fotoperíodo crítico entre 11 e 14 h (Ferreira et al., 1995; Magalhães, 1996; Bagchi et al., 1997; Geldre et al., 1997; Marchese et 
al., 2002) e mecanismo fotossintético do tipo C3 (Marchese et al., 2005). A sua reprodução ocorre predominantemente por fecundação cruzada, multiplicando-se por sementes e propagando-se vegetativamente com facilidade (Magalhães et al., 1999).

As folhas de $A$. annua são importante fonte de artemisinina, uma lactona sesquiterpênica eficaz contra cepas resistentes de Plasmodium falciparum causador da malária cerebral (Ferreira \& Janick, 1996; Marchese \& Rehder, 2001; Marchese et al., 2005), além de ser seletivamente citotóxica para células cancerígenas (Ferreira, 2004; Lai \& Singh, 2006; Efferth, 2007; Arsenault et al., 2008; Oh et al., 2009). Por ser aromática, a espécie também é fonte de óleo essencial, comercialmente utilizado em perfumaria e cosméticos (Jain et al., 1996; Magalhães et al., 2004). A China e o Vietnam produzem cerca de $70 \%$ da oferta global de artemisinina (Ferreira \& Luthria, 2010), porém, com a crescente demanda pela substância a oferta está aquém da procura (Erdemoğlu et al., 2007), uma vez que, os rendimentos relativamente baixos e inconsistentes, limitam sua produção em larga escala (Charles \& Simon, 1990; Jain et al., 1996).

$A$. annua é originária da China (Marchese et al., 2005) e sua introdução no Brasil aconteceu no final da década de 80 a partir de sementes procedentes da Europa e da China (Magalhães, 1996). Entretanto, com a ampla variabilidade existente, os primeiros ensaios apresentaram plantas com crescimento e morfologia heterogêneos, além de baixos rendimentos de artemisinina, aproximadamente $1 \mathrm{~kg} \mathrm{ha}^{-1}$, devido à influência fotoperiódica e o florescimento precoce. Com a introdução de genótipos superiores do Vietnam e as técnicas de seleção na MEDIPLANT, na Suíça, foi possível o desenvolvimento de híbridos específicos para as condições brasileiras (Magalhães et al., 2004). A variedade Artemis é destacada por Graham et al. (2010) como sendo um desses híbridos, considerado atualmente o líder em produção de artemisinina.

Em experimentos realizados em Pato Branco por Marchese (2006) com o objetivo de avaliar o rendimento de biomassa foliar e artemisinina para o acesso $2 / 39 \times 1 \mathrm{~V}$ de $A$. annua naquela região, foi observado que os rendimentos de fitomassa e artemisinina encontrados em Pato Branco-PR foram superiores aqueles encontrados para o mesmo acesso por Magalhães et al. (1999) em Campinas-SP. O teor de artemisinina na biomassa foliar foi o mesmo em Pato Branco e Campinas, sugerindo que o rendimento de artemisinina $(\mathrm{kg}$ ha-1) está mais associado aos ganhos em biomassa foliar provocados pelas temperaturas mais amenas no sudoeste do Paraná, pois espécies $C_{3}$ adaptam- se melhor a esses climas. Divergências no comportamento fisiológico desta espécie em relação à influência de fatores ambientais sugerem que seu comportamento não é padrão, sendo variável para diferentes genótipos e locais de cultivo (Ferreira et al., 1995; Marchese \& Rehder, 2001).

Devido à crescente demanda nacional e internacional por artemisinina e análogos, e a sua produção em escala industrial ser um fator limitante pelos baixos teores encontrados em populações base de $A$. annua, torna-se necessário conhecer a natureza e a magnitude da variabilidade genética intra-específica disponível nas variedades, buscando identificar acessos promissores. Assim, o objetivo deste trabalho foi estimar a variabilidade genética de três variedades de $A$. annua, a partir de avaliações agronômicas, fisiológicas e fitoquímicas, e indicar acessos promissores para serem utilizados em hibridações.

\section{MATERIAL E MÉTODO}

O experimento foi conduzido na área experimental do curso de Agronomia da Universidade Tecnológica Federal do Paraná, localizada em Pato Branco-PR, latitude $26^{\circ} 11^{\prime} \mathrm{S}$, longitude $52^{\circ} 36^{\prime} \mathrm{W}$, altitude de $760 \mathrm{~m}$, clima Cfa subtropical. Em 13 de julho de 2009 as variedades Artemis, 2/39x5x3M e $2 / 39 \times 1 \mathrm{~V}$ de $A$. annua foram semeadas em grades com 96 tubetes contendo $130 \mathrm{~g}$ de substrato orgânico Tecnomax® esterilizado. Utilizou-se 192 tubetes por variedade e estes foram mantidos em estufa plástica sob fotoperíodo de 15 horas para evitar o florescimento das plantas.

Em 08 de outubro de 2009, quando as plantas atingiram a altura aproximada de $20 \mathrm{~cm}$, foram transplantadas para campo. Os tratamentos foram as três variedades representadas por 15 plantas/acessos cada, dispostas no delineamento experimental inteiramente casualizado.. A área experimental utilizada foi de $1050 \mathrm{~m}^{2}$, sendo o espaçamento de $1 \times 1 \mathrm{~m}$ entre as plantas e de $3 \mathrm{~m}$ entre as variedades.

No dia 27 de janeiro de 2010 foi feita a primeira seleção das plantas que, visualmente, apresentavam maior porte e maior quantidade de folhas. Nesta etapa foram selecionadas 50 plantas de cada variedade e identificadas com etiquetas de acrílico amarradas no ápice das plantas, sendo de A1 a A50 para a variedade Artemis, de B1 a B50 para a variedade $2 / 39 \times 5 \times 3 \mathrm{M}$, e de $\mathrm{C} 1$ a C50 para a variedade $2 / 39 \times 1 \mathrm{~V}$. Quando $50 \%$ das plantas selecionadas iniciaram a emissão dos botões florais, fez-se uma segunda seleção visual, dentre as 50 plantas selecionadas inicialmente, elegendo as 15 plantas que apresentavam maior altura e maior biomassa foliar em cada variedade para avaliação

Rev. Bras. PI. Med., Campinas, v.16, n.2, supl. I, p.356-363, 2014. 
de caracteres agronômicos.

Os caracteres aferidos foram: altura da planta $(\mathrm{Ht}, \mathrm{m})$; altura de inserção do primeiro par de ramos plagiotrópicos $(\mathrm{Hi}, \mathrm{m})$; altura do dossel $(\mathrm{Hd}, \mathrm{m})$; diâmetro da seção inferior do dossel (Di, $\mathrm{m})$; diâmetro da seção média do dossel (Dm, m); diâmetro da seção superior do dossel (Ds, m); diâmetro do caule (DC, $\mathrm{cm}$ ); número de ramificações (NR), e volume do dossel (Vc, $\left.\mathrm{m}^{3}\right)$. O volume do dossel foi estimado pela equação $V_{c}=\pi D i^{2} \mathrm{Hd} / 12$, conforme metodologia utilizada por Favarin et al. (2002).

As variáveis fisiológicas determinadas foram: taxa de assimilação de $\mathrm{CO}_{2}\left(P_{\mathrm{N}}, \mu \mathrm{mol} \mathrm{CO}_{2}\right.$ $\left.\mathrm{m}^{-2} \mathrm{~s}^{-1}\right)$, condutância estomática $\left(g_{\mathrm{s}}, \mathrm{mol} \mathrm{H}_{2} \mathrm{O} \mathrm{m}^{-2} \mathrm{~s}^{-1}\right)$, concentração intracelular de $\mathrm{CO}_{2}\left(\mathrm{C}_{\mathrm{i}}, \mu \mathrm{mol} \mathrm{CO}_{2} \mathrm{~mol}^{-1}\right)$, taxa de transpiração $\left(E, \mathrm{mmol} \mathrm{H}_{2} \mathrm{O} \mathrm{m}^{-2} \mathrm{~s}^{-1}\right)$, e eficiência no uso de água (WUE, \%), além da medição daárea foliar $\left(\mathrm{AF}, \mathrm{cm}^{2}\right)$. A avaliação das trocas gasosas foi realizada nas oito plantas de cada variedade, as quaisapresentavam maior volume de dossel, utilizando-se um sistema de medição de trocas gasosas equipado com analisador infravermelho de gases (IRGA) modelo LI-6400XT (LI-COR, Lincoln, Nebrasca - USA), com injetor automático de $\mathrm{CO}_{2}$ e fonte artificial de luz vermelho e azul. As condições microclimáticas na câmara de medidas das amostras foram mantidas constantes nas medições, $1200 \mu \mathrm{mol} \mathrm{m}^{-2} \mathrm{~s}^{-1}$ de PAR (photosynthetic active radiation/radiação fotossinteticamente ativa), UR $53 \pm 7 \%, 400 \mathrm{ppm}$ de $\mathrm{CO}_{2}$ e temperatura das folhas em torno de $29,5 \pm 2,8{ }^{\circ} \mathrm{C}$. A amostragem de oito plantas foi definida devido à dificuldade de realização desta avaliação em um grande número de plantas, em função da fragilidade das folhas de $A$. annua que, quando acopladas ao IRGA, se desprendem facilmente dos galhos interrompendo a mensuração das trocas gasosas. As mensurações iniciaram-se aproximadamente as $10 \mathrm{~h}$ da manhã e foram realizadas nas folhas completamente desenvolvidas e sadias a partir do terço médio das plantas. Devido ao formato recortado das folhas de $A$. annua e a necessidade de se estimar a área foliar nas avaliações de trocas gasosas, as folhas foram fotografadas e o cálculo da área (apenas aquela delimitada na câmara do IRGA) foi feito com o auxílio da ferramenta de cálculo de área do software livre GIMP (GNU Image Manipulation Program).

Baseando-se nas características agronômicas superiores, 15 plantas de cada uma das variedades $2 / 39 \times 5 \times 3 \mathrm{M}$ e $2 / 39 \times 1 \mathrm{~V}$ foram clonadas por estaquia mantidas em casa de vegetação sob fotoperíodo de 15 horas, para que, em trabalhos futuros, possam ser utilizadas em cruzamentos. Devido a problemas na colheita do experimento, a variedade Artemis foi descartada e não fez parte das avaliações fitoquímicas.
A colheita foi realizada no dia 20 de março de 2010 , quando mais de $50 \%$ das plantas iniciaram o florescimento. As plantas foram cortadas rente ao solo e colocadas para secar até peso constante em estufa com circulação de ar e temperatura de $\pm 35^{\circ} \mathrm{C}$. Após secagem, as folhas foram segregadas dos caules para realização das análises fitoquímicas.

Os caracteres fitoquímicos avaliados foram: rendimento de óleo essencial (OLS, L ha-1), teor de artemisinina (ART, \%), teor de dihidro-epideoxiartenuína B (DIH, \%), e teor de deoxiartemisinina (DEO, \%).

A extração do óleo essencial foi realizada no Laboratório de Bioquímica e Fisiologia Vegetal da Universidade Tecnológica Federal do Paraná. Primeiramente, $150 \mathrm{~g}$ de massa seca de folhas de cada acesso das variedades B e $\mathrm{C}$ de $A$. annua foram transferidas para um balão de $2 \mathrm{~L}$ contendo 1,5 $\mathrm{L}$ de água destilada, acoplado a um sistema Clevenger, onde procedeu-se a hidrodestilação durante 1 h e 30 min após o início da condensação. Depois de aferir o volume de óleo extraído, este foi armazenado hermeticamente em vidros âmbar em geladeira a $4^{\circ} \mathrm{C}$.

As análises de artemisinina e análogos das folhas foram realizadas na Divisão de Fitoquímica do Centro Pluridisciplinar de Pesquisas Químicas, Biológicas e Agrícolas da Universidade Estadual de Campinas (CPQBA/UNICAMP). Os extratos foram obtidos a partir de $0,250 \mathrm{~g}$ de folhas secas e moídas extraídas com $5 \mathrm{~mL}$ de diclorometano por 2 minutos em Ultra Turrax (Marca Quimis modelo Q-252, São Paulo, Brasil), e em seguida, $2 \times 5 \mathrm{~mL}$ de metanol, por 3 minutos e 6000 rpm à temperatura ambiente. $O$ extrato foi filtrado a vácuo em funil de placa porosa com papel de filtro e evaporado a secura em rotaevaporador (Marca Büchi modelo R2, Flawil, Switzerland).

$\mathrm{Na}$ etapa de purificação do extrato, cartuchos de Florisil® (Strata 8B-So13-hCh, Phenomenex, Califórnia, USA), foram completados com mais $5 \mathrm{~g}$ de Florisil $囚$ FX 0284-1 (60-100 Mesh) e depois de conectados ao sistema de extração a vácuo (Manifold) (J. T. Baker, New Jersey, USA) foram condicionados com $10 \mathrm{~mL}$ de hexano. Em seguida, introduziu-se o extrato dissolvido em 2 $\mathrm{mL}$ de hexano, eluindo com $3 \mathrm{~mL}$ de hexano e $60 \mathrm{~mL}$ de diclorometano, coletando as frações separadamente. A fração de diclorometano foi evaporada à secura sob vácuo em evaporador rotativo e ressuspendida em balão volumétrico de $5 \mathrm{~mL}$ com metanol grau CLAE. As amostras foram filtradas e analisadas em triplicata em cromatógrafo líquido de alta eficiência acoplado ao detector de índice de refração por (CLAE/IR). Foi utilizado um cromatógrafo líquido Waters (Massachusetts, USA), bomba Waters 515, válvula injetora Rheodyne,

Rev. Bras. PI. Med., Campinas, v.16, n.2, supl. I, p.356-363, 2014. 
com alça de amostragem de $20 \mu \mathrm{l}$. O sistema foi acoplado a um detector de índice de refração Waters 2414; temperatura interna do detector $35^{\circ} \mathrm{C}$. Os dados cromatográficos foram analisados usando-se software Empower pro build 1154/Waters. Utilizouse coluna com fase estacionária ciano, Luna CN 5 um 250 x 4,6 mm (Phenomenex, Califórnia, USA); fase móvel $\mathrm{H}_{2} \mathrm{O}$ :Metanol (60:40 v/v); modo isocrático e vazão $1,0 \mathrm{~mL} / \mathrm{min}$. As quantificações do teor de artemisinina dos extratos foram realizadas utilizando a metodologia validada desenvolvida por Celeghini et al. (2009), a partir do método do padrão externo.

$\mathrm{Na}$ comparação de médias, foram classificados como superiores aqueles acessos que apresentaram média superior à média geral mais o desvio padrão e inferiores aqueles que apresentaram média inferior a média geral menos o desvio padrão.

Para a realização das estimativas de distância genética foram geradas matrizes de dissimilaridade empregando a Distância Euclidiana, com o auxílio do software estatístico Genes (Cruz, 2001). Com base nessas matrizes foram feitas as análises de agrupamento pelo método de otimização de Tocher e pelo método hierárquico UPGMA (Unweighted Pair-Group Method Using Arithmetic Averages). Pelo método UPGMA foram obtidos os dendrogramas de dissimilaridade intravarietal para os caracteres fitoquímicos, utilizando-se o programa NTSYS pc 2.1 (Rohlf, 2000). Os grupos formados nos dendrogramas foram separados a partir do ponto de corte feito com base na distância genética média obtida. A estabilidade estatística dos agrupamentos foi estimada pela análise de Bootstrapping com 1.000 simulações. Além disso, avaliou-se a importância relativa dos caracteres para divergência genética pelo método de Singh (1981).

\section{RESULTADOS E DISCUSSÃO}

Ao comparar o desempenho dos acessos da variedade Artemis para os caracteres agronômicos, observa-se que no caráter altura de planta $(\mathrm{Ht})$ os acessos considerados superiores dentro da variedade foram A10 (2,09 m) e A18 $(2,11 \mathrm{~m})$. Quanto ao caráter volume de dossel (Vc) foram

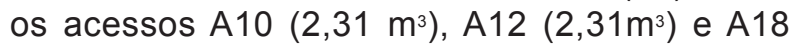
$\left(2,40 \mathrm{~m}^{3}\right)$ que apresentaram o melhor desempenho. Os acessos que apresentaram desempenho inferior para o caráter altura de planta, A7 $(1,89 \mathrm{~m}), \mathrm{A} 22$ (1,88 m), A33 (1,89 m) e A46 (1,90 m) também foram inferiores para o volume de dossel A7 (1,64 $\left.\mathrm{m}^{3}\right), A 22$ $\left(1,67 \mathrm{~m}^{3}\right)$, A33 $\left(1,75 \mathrm{~m}^{3}\right)$ e A46 $\left(1,71 \mathrm{~m}^{3}\right)$, indicando que plantas mais altas possuem maior volume de dossel, o que já era esperado.

$\mathrm{Na}$ variedade $2 / 39 \times 5 \times 3 \mathrm{M}$ apresentaram desempenho superior para os caracteres volume de dossel $(\mathrm{Vc})$ e rendimento de óleo essencial (OLS) os acessos B14 (2,12 $\mathrm{m}^{3}$ e 55,26 L ha-1, respectivamente) e B24 (2,57 $\mathrm{m}^{3}$ e $71,85 \mathrm{~L} \mathrm{ha}^{-1}$, respectivamente). O acesso $\mathrm{B} 14$ foi inferior para caracteres fisiológicos, apresentando as menores médias para taxa de assimilação de $\mathrm{CO}^{2}\left(P_{\mathrm{N}}: 6,07\right.$ $\left.\mu \mathrm{mol} \mathrm{CO} \mathrm{Cm}^{-2} \mathrm{~s}^{-1}\right)$, condutância estomática $\left(g_{\mathrm{s}}: 0,08\right.$ $\left.\mathrm{H}_{2} \mathrm{O} \mathrm{m}^{-2} \mathrm{~S}^{-1}\right)$, concentração intracelular de $\mathrm{CO}_{2}\left(\mathrm{C}_{\mathrm{i}}\right.$ : $255,13 \mu \mathrm{mol} \mathrm{CO}_{2} \mathrm{~mol}^{-1}$ ) e taxa de transpiração ( $E$ : $1,92 \mathrm{mmol} \mathrm{H}_{2} \mathrm{O} \mathrm{m}^{-2} \mathrm{~s}^{-1}$ ). Já o acesso B35 apresentou o melhor desempenho para estes caracteres: taxa de assimilação de $\mathrm{CO}^{2}\left(P_{\mathrm{N}}: 19,00 \mu \mathrm{mol} \mathrm{CO} \mathrm{Cm}^{-2}\right.$ $\left.\mathrm{s}^{-1}\right)$, condutância estomática $\left(g_{\mathrm{s}}: 0,41 \mathrm{H}_{2} \mathrm{O} \mathrm{m} \mathrm{m}^{-2} \mathrm{~s}^{-1}\right)$ e taxa de transpiração $\left(E: 9,80 \mathrm{mmol} \mathrm{H}_{2} \mathrm{O} \mathrm{m}^{-2} \mathrm{~s}^{-1}\right)$. Nos caracteres fitoquímicos, apresentaram melhor desempenho para teor de artemisinina (ART) os acessos B7 (0,88\%), B33 (0,95\%) e B35 (0,89\%).

Com relação ao desempenho dos acessos da variedade $2 / 39 \times 1 \mathrm{~V}$, observa-se que estes apresentaram as maiores médias para o caráter altura de planta $(\mathrm{Ht})$ e que os acessos superiores dentro da variedade foram C4 (2,84 m), C10 (2,64 m), C17 (2,87 m), C31 (3,00 m) e C45 (2,92 m). Quanto ao rendimento de óleo essencial (OLS), o acesso C32 se mostrou superior com 71,23 L ha-1. Para os teores de artemisinina (ART) e análogos (DIH e DEO), o acesso que apresentou desempenho superior foi C5 com 1,12\%.

Na tabela 1 encontram-se os agrupamentos obtidos pelo método de otimização de Tocher utilizando a distância Euclidiana. Com base nos caracteres agronômicos, observa-se a formação de seis grupos na variedade Artemis, dois grupos na variedade $2 / 39 \times 5 \times 3 \mathrm{M}$ e seis grupos na variedade 2/39x1V. Observa-se que a formação dos grupos se deu de acordo com o desempenho superior e inferior dos acessos, conforme apresentado anteriormente. Na variedade $2 / 39 \times 5 \times 3 \mathrm{M}$, o grupo II foi formado unicamente pelo acesso B24, em vista o desempenho superior deste acesso para a maioria dos caracteres agronômicos aferidos.

Quanto aos caracteres fisiológicos foram formados dois grupos na variedade Artemis, quatro grupos na variedade $2 / 39 \times 5 \times 3 \mathrm{M}$ e dois grupos na variedade $2 / 39 \times 1 \mathrm{~V}$ (Tabela 1 ). $\mathrm{Na}$ variedade 2/39x5x3M, o grupo III foi formado apenas pelo acesso B35, que apresentou desempenho superior para a maioria dos caracteres fisiológicos avaliados, enquanto que, o grupo IV foi formado apenas pelo acesso B14, cujo desempenho foi inferior para a maioria dos caracteres fisiológicos.

A formação desses grupos representa valiosa informação na escolha de genitores dentro dos programas de melhoramento, pois as novas populações híbridas a serem estabelecidas devem ser embasadas na magnitude de suas dissimilaridades e no potencial "per se" dos genitores

Rev. Bras. PI. Med., Campinas, v.16, n.2, supl. I, p.356-363, 2014. 
(Bertan et al., 2006).

Os caracteres fitoquímicos foram agrupados pelo método hierárquico UPGMA (Unweighted Pair-Group Method Using Arithmetic Averages). O dendrograma de dissimilaridade entre 15 acessos da variedade $2 / 39 \times 5 \times 3 \mathrm{M}$, a partir de quatro caracteres fitoquímicos, teve o ponto de corte $(\operatorname{dgm}=2,64)$ evidenciando a formação de quatro grupos (Figura 1A). O primeiro grupo foi constituído por B6 + B43 e B19. O segundo grupo foi formado apenas por B24, que apresentou o maior OLS $\left(71,85 \mathrm{~L} \mathrm{ha}^{-1}\right)$. O terceiro grupo por B7 + B13, B15, B23, B26 + B28 e B35. O quarto grupo foi formado por B10 + B33, B14 + B20. O agrupamento mais consistente compreendeu os 4 grupos formados em $100 \%$ das simulações. O coeficiente de correlação cofenética $(r=0,71)$ não apresentou um bom ajuste entre o dendrograma e a sua matriz original.

O ponto de corte no dendrograma da dissimilaridade da variedade 2/39x1V (dgm $=2,49)$ caracterizou a formação de quatro grupos (Figura 1B), sendo que, o primeiro grupo foi subdividido em dois subgrupos, o subgrupo $\mathrm{A}$ formado por $\mathrm{C} 1, \mathrm{C} 14$ + C38 e C4; e o subgrupo B formado por C16 + C26, C17, C24, C31 + C45; o segundo grupo foi formado apenas por $\mathrm{C} 32$; o terceiro grupo apenas por $\mathrm{C} 10 \mathrm{e}$ o quarto grupo apenas por C5. Os acessos C32, C10 e C5 foram os mais dissimilares dentro da variedade, para os caracteres fitoquímicos avaliados.

A variabilidade interpopulacional para 0 rendimento de óleo essencial em plantas de $A$. annua de diferentes origens foi observada por Holm et al. (1997), que verificaram variação no conteúdo de 0,4 a $0,9 \%$ sobre o peso seco.

Delabays et al. (2001) evidenciaram a variabilidade encontrada para o teor de artemisinina ao reportar que genótipos originários de 14 locais diferentes apresentavam teores variando de 0,02 a $1,38 \%$ sobre peso seco. Além destes, Sangwan et al. (1999) também encontraram variabilidade entre os genótipos para os teores de óleo essencial e artemisinina, com o conteúdo de óleo essencial variando de 0,69 a 2,93 ( $\mathrm{mg} \mathrm{g}^{-1}$ de peso fresco), e o de artemisinina de 0,09 a 0,64 ( $\mathrm{mg} \mathrm{g}^{-1}$ de peso seco). O acesso C32 apresentou o maior OLS $(71,23 \mathrm{~L}$ ha-1) e C5 apresentou o maior ART $(1,12 \%)$. De acordo com Delabays et al. (2001), a variabilidade genética existente no conteúdo de artemisinina tem sido usada com sucesso em programas de melhoramento buscando aperfeiçoar a produção agrícola da substância; assim, plantas com mais de $1 \%$ de artemisinina devem ser propagadas e usadas em programas de melhoramento tendo em vista a alta herdabilidade verificada para este caráter $(0,98)$.

A Tabela 2 apresenta a importância relativa dos caracteres para a divergência genética entre as variedades segundo o método de Singh (1981). Observa-se que as características que mais contribuíram foram: número de ramificações $(99,4 \%)$, concentração intracelular de $\mathrm{CO}_{2}(99,6 \%)$ e rendimento de óleo essencial (100\%) (Tabela 2). O número de ramificações é um caráter agronômico de fácil mensuração, sem custo algum e avaliado quando as plantas ainda estão no campo. A variabilidade para o rendimento de óleo essencial

TABELA 1. Agrupamento dos acessos das variedades Artemis, 2/39x5x3M e 2/39x1V de Artemisia annua L. a partir de caracteres agronômicos e fisiológicos, pelo método de agrupamento de Tocher, utilizando a distância Euclidiana como medida de distância genética. UTFPR, Pato Branco - PR, 2010.

\begin{tabular}{cccc}
\hline \multicolumn{3}{c}{ CARACTERES AGRONÔMICOS } \\
\hline \multicolumn{5}{c}{ ACESSOS } \\
\hline Grupos & Artemis & 2/39x5x3M & 2/39x1V \\
\hline I & A10, A21, A38, A12, & B15, B35, B13, B26, B33, B28, B20, B43, & C1, C26, C31, C4, C5, C32, \\
II & A18 & B7, B19, B10, B6, B14, B23 & C38, C10, C13, C45 \\
III & A9, A28, A4 & B24 & C14 \\
IV & A33, A46, A45 & & C23 \\
V & A22, A26 & C16 \\
VI & A5 & CARACTERES FISIOLÓGICOS & C17 \\
\hline \multicolumn{5}{c}{ ACESSOS } \\
\hline Grupos & Artemis & 2/39x5x3M & C14, C16, C1, C10, C26, C17, \\
\hline I & A22, A45, A5, A28, & B20, B43, B28, B23 \\
II & A12, A4, A7 & B15, B24 & C13 \\
III & A46 & B35 & \\
IV & & B14 & \\
\hline
\end{tabular}

Rev. Bras. PI. Med., Campinas, v.16, n.2, supl. I, p.356-363, 2014. 

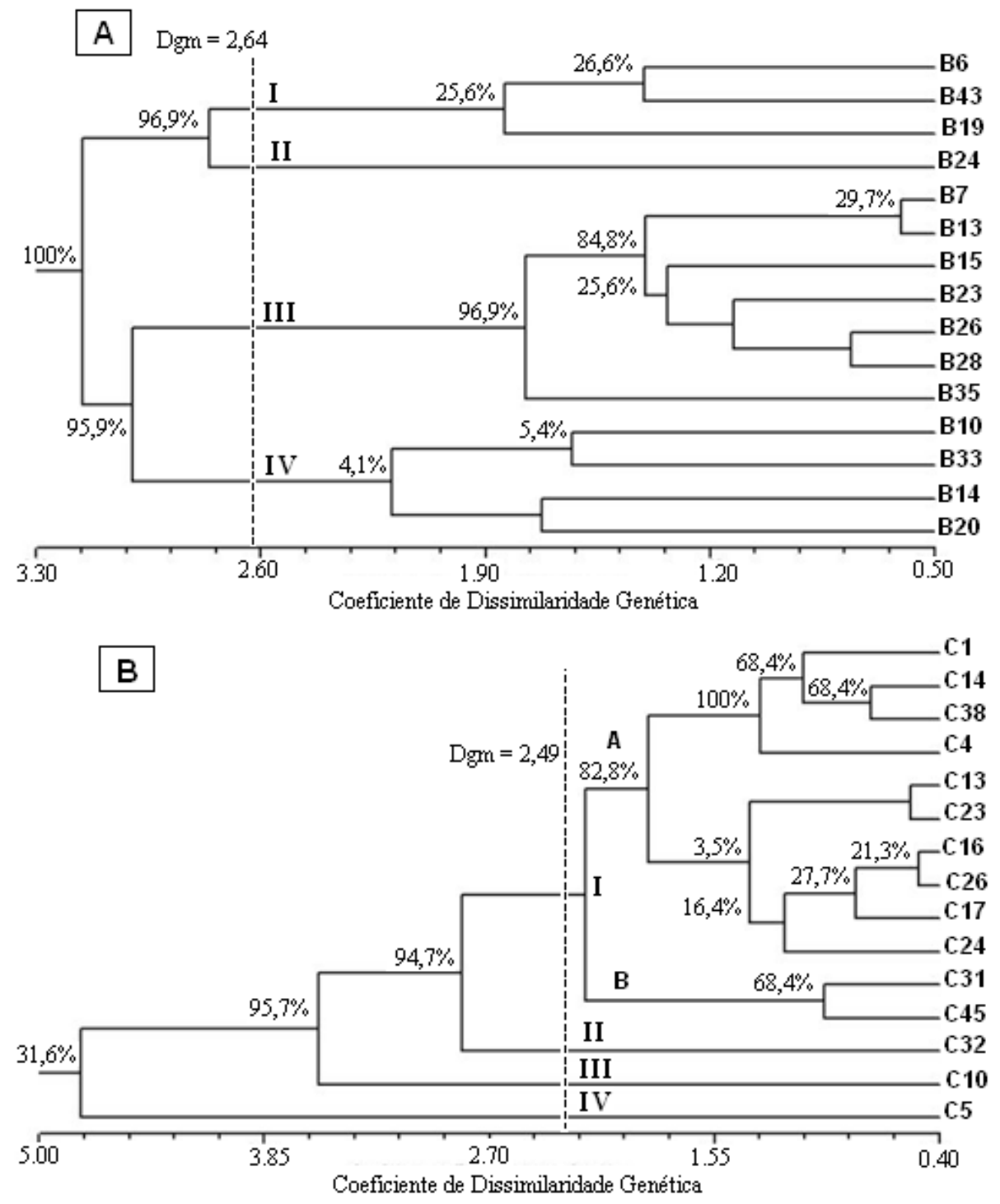

FIGURA 1. Dendrogramas resultantes da análise de agrupamento de quinze acessos das variedades $2 / 39 \times 5 \times 3 \mathrm{M}$ (A) e 2/39x1V (B) de Artemisia annua L., a partir de quatro caracteres fitoquímicos, utilizando a Distância Euclidiana e o método de agrupamento de UPGMA. Os valores encontrados nos grupos indicam o valor percentual de vezes que os genótipos agruparam juntos em 1000 ciclos de bootstraping. Os valores dos coeficientes de correlação cofenética (r) foram de 0,71 e 0,90, respectivamente. UTFPR, Pato Branco, 2010.

também foi encontrada por Holm et al. (1997), onde ele afirma que esta variação vai depender da origem das sementes, do local de cultivo e da época de colheita.

Após serem desconsiderados os caracteres: número de ramificações, concentração intracelular de $\mathrm{CO}_{2}$ e rendimento de óleo essencial, observou-se que houve nova distribuição da importância relativa dos caracteres para a dissimilaridade genética nas variedades. Desta forma, os caracteres que mais contribuíram para a dissimilaridade foram: o volume do dossel $(52,50 \%)$, condutância estomática $(99,24 \%)$, e teor de deoxiartemisinina $(93,07 \%)$. O volume de dossel é um caráter fácil de ser estimado a partir da aplicação da equação $\mathrm{Vc}=\pi \mathrm{Di} \mathrm{i}_{2} \mathrm{Hd} / 12$, em que se utilizam as medidas de altura do dossel e o diâmetro do dossel inferior da planta.A deoxiartemisinina é obtida no mesmo processo de extração de artemisinina.

Os demais caracteres apresentaram pouca ou nenhuma importância relativa e, de acordo com Bertan et al. (2006), as variáveis com estimativas de contribuição relativa de pequena magnitude não são consistentes na quantificação da dissimilaridade genética, e podem significar pouco progresso genético no melhoramento. 
TABELA 2. Contribuição relativa de caracteres agronômicos, fisiológicos e fitoquímicos, na divergência entre variedades de Artemisia annua L. UTFPR, Pato Branco - PR, 2010.

\begin{tabular}{|c|c|c|c|c|}
\hline \multicolumn{5}{|c|}{ CARACTERES AGRONÔMICOS } \\
\hline VARIÁVEL & S.j. & VALOR \% & S.j. & VALOR \% \\
\hline Altura da planta & 1,3926 & 0,0119 & 0,5370 & 20,156 \\
\hline Altura de inserção dos ramos & 0,497 & 0,0043 & 0,0028 & 0,1058 \\
\hline Altura do dossel & 14,3888 & 0,1234 & 0,4672 & 17,5346 \\
\hline Diâmetro da seção inferior do dossel & 13,3926 & 0,1149 & 0,0469 & 1,7637 \\
\hline Diâmetro da seção média do dossel & 16,4006 & 0,1407 & 0,0294 & 1,1063 \\
\hline Diâmetro da seção superior do dossel & 9,336 & 0,0801 & 0,1759 & 6,6023 \\
\hline Volume do dossel & 13,0748 & 0,1122 & 1,3991 & 52,5078 \\
\hline Diâmetro do caule & 1,44 & 0,0124 & 0,0059 & 0,2235 \\
\hline Número de ramificações & 11586 & 99,4001 & - & - \\
\hline \multicolumn{5}{|c|}{ CARACTERES FISIOLÓGICOS } \\
\hline VARIÁVEL & S.j. & VALOR \% & S.j. & VALOR \% \\
\hline Área foliar & 1,53816 & 0,0297 & 1,5381 & 0,0695 \\
\hline Taxa de assimilação de $\mathrm{CO}_{2}$ & 11,31673 & 0,2189 & 11,3167 & 0,5116 \\
\hline Condutância estomática & 0,21952 & 0,0042 & 2195,19 & 99,2423 \\
\hline Concentração intracelular de $\mathrm{CO}_{2}$ & 5154,204 & 99,6777 & - & - \\
\hline Taxa de transpiração & 3,58649 & 0,0694 & 3,5864 & 0,1621 \\
\hline Eficiência no uso de água & 0,003192 & 0,0001 & 0,3192 & 0,0144 \\
\hline \multicolumn{5}{|c|}{ CARACTERES FITOQUÍMICOS } \\
\hline VARIÁVEL & S.j. & VALOR \% & S.j. & VALOR \% \\
\hline Rendimento de óleo essencial & 1401,724 & 100 & - & - \\
\hline Teor de artemisinina & 0,000044 & - & 0,000044 & 6,2778 \\
\hline Teor de dihidro-epideoxiartenuína B & 0,000005 & - & 0,000005 & 0,6506 \\
\hline Teor de deoxiartemisinina & 0,000007 & - & 0,000659 & 93,0716 \\
\hline
\end{tabular}

S.j. = Estimativa da contribuição relativa de cada característica.

\section{CONCLUSÕES}

Os genitores mais divergentes e que apresentaram as maiores médias para os caracteres fitoquímicos foram B24, C5 e C32, sendo estes os mais indicados em um programa de melhoramento.

As hibridações B24 x C5, B24 x C32 e C5 x C32 podem ser consideradas as mais promissoras na obtenção de populações segregantes desejadas.

\section{AGRADECIMENTO}

A Coordenação de Aperfeiçoamento de Pessoal de Nível Superior pela concessão da bolsa do primeiro autor.

\section{REFERÊNCIA}

ARSENAULT, P.R. et al. Recent Advances in Artemisinin Production Through Heterologous Expression. Current Medicinal Chemestry, v.15, n.27, p.2886, 2008.

BAGCHI, G.D. et al. Arteether: a potent plant growth inhibitor from Artemisia annua. Phytochemistry., v.45, n.6, p.1131-1133, 1997.

BERTAN, I. et al. Dissimilaridade genética entre genótipos de trigo avaliados em cultivo hidropônico sob estresse por alumínio. Bragantia, v.65, n.1, p.55-63, 2006.

BRISIBE, E.A. et al. Nutritional characterisation and antioxidant capacity of different tissues of Artemisia annua L. Food Chemistry, v.115, p.1240-1246, 2009. CELEGHINI, R.M.S. et al. Desenvolvimento e validação de metodologia analítica por CLAE-IR para determinação de artemisinina em Artemisia annua L. Quimica Nova, v.32, n.4, p.875-878, 2009.

CHARLES, D.J.; SIMON, J.E. Germoplasm variation in artemisinin content of Artemisia annua using na alternative method of artemisinin analysis from crude plant extracts. Journal of Natural Products., v.53, n.1, p.157-160, 1990.

CRUZ, C.D. Programa Genes: Aplicativo computacional em genética e estatística. Viçosa, Editora UFV, 2001. $648 p$.

DELABAYS, N. et al. The genetics of artemisinin content in Artemisia annua L. and the breeding of high yielding cultivars. Current Medicinal Chemistry, v.8, n.15, p.1795-1801, 2001.

EFFERTH, T. Willmar Schwabe Award 2006: Antiplasmodial and Antitumor Activity of Artemisinin - From Bench to Beside. Planta Medica, v.73, n.4, p. 299-309, 2007.

ERDEMOĞLU, N. et al. Determination of Artemisinin in Selected Artemisia L. Species of Turkey by Reversed Phase HPLC. Records of Natural Products, v.1, n.2-3. p.36-43, 2007.

FERREIRA, J.F.S. et al. Developmental studies of Artemisia annua: flowering and artemisinin production under greenhouse and field conditions. Planta Medica, 
v.61, n.2, p.167-170, 1995

FERREIRA, J.F.S.; JANICK J. Distribution of artemisinin in Artemisia annua. In: JANICK, J. (Ed.). Progress in new crops. Arlington: ASHS Press, 1996. p.579-584.

FERREIRA, J.F.S. Artemisia annua L.: The hope against malaria and câncer. Medicinal and aromatic plant: Production, business e applications. 2004. Disponível em: <http://www.ars.usda.gov/SP2UserFiles/ person/34667/Ferreira-ArtemisiavsMalariaandCancer. pdf>. Acesso em: 10 nov. 2010.

FERREIRA, J.F.S.; LUTHRIA, D.L. Drying Affects Artemisinin, Dihydroartemisinic Acid, Artemisinic Acid, and the Antioxidant Capacity of Artemisia annua L. Leaves. Journal of Agricultural and Food Chemistry, v.58, n.3, p.1691-1708, 2010.

GELDRE, E.V. et al. State of the art of the production of the antimalarial compound artemisinin in plant. Plant Molecular Biology, v.33, n.2, p.199-209, 1997.

GRAHAM, I.A. et al. The Genetic Map of Artemisia annua L.Identifies Loci Affecting Yield of the Antimalarial Drug Artemisinin. Science. v.327, p. 328-331. 2010.

HOLM, Y. et al. Variation in the Essential Oil Composition of Artemisia annua L. of Different Origin Cultivated in Finland. Flavour and fragrance journal, v.12, p.241246, 1997.

JAIN, D.C. et al. Isolation of high artemisinin-yielding clones of Artemisia annua. Phytochemistry, v.43, n.5, p.993-1001, 1996.

LAI, H.; SINGH, N. P. Oral artemisinin prevents and delays the development of 7,12-dimethylbenz[a]anthracene (DMBA)-induced breast cancer in the rat. Cancer Letters, v.231, n.1, p.43-48, 2006.

MAGALHÃES, P.M. Seleção, melhoramento e nutrição da Artemisia annua L., para cultivo em região intertropical. 1996. 132 p. Tese (Doutorado). Universidade Estadual de Campinas, Campinas.

MAGALHÃES, P.M. et. al. New hybrid lines of the antimalarial species Artemisia annua L. Acta Horticulturae 502, 1999.

MAGALHÃES, P.M. et al. Yields of antimalarial Artemisia annua L. species. Acta Horticulturae 629, 2004.

MARCHESE, J.A.; REHDER, V.L.G. Influência da temperatura na produção de artemisinina em Artemisia annua L. Revista Brasileira de Plantas Medicinais, v.4, n.1, p.89-93, 2001.

MARCHESE, J.A. et al. Flowering of Artemisia annua L. Plants Submitted to Different Photoperiod and Temperature Conditions. Acta Horticulturae 569, 2002.

MARCHESE, J.A. et al. Carbon isotope composition and leaf anatomy as a tool to characterize the photosynthetic mechanism of Artemisia annua L. Brazilian Journal of Plant Physiology, v.17, n.1, p.187-190, 2005.

MARCHESE, J.A. Caracterização do mecanismo fotossintético e aspectos relacionados à floração de Artemisia annua L. 2006. 68p. Tese (Doutorado). Departamento de Horticultura: Universidade Estadual Paulista, Botucatu.

$\mathrm{OH}, \mathrm{S}$. et al. Synthesis and anti-cancer activity of covalent conjugates of artemisinin and a transferrin-receptor targeting peptide. Cancer Letters, v.274. p.33-39, 2009.

SANGWAN, R.S. et al. RAPD profile based genetic characterization of chemotypic variants of Artemisia annua L. Biochemistry and Molecular Biology International, v.47, n.6, p.935-944, 1999.

SINGH, D. The relative importance of characters affecting genetic divergence. The Indian Journal of Genetic and Plant Breeding, v.41, p.237-245, 1981.

Rev. Bras. PI. Med., Campinas, v.16, n.2, supl. I, p.356-363, 2014. 